\title{
Hemoperitoneum secondary to splenic rupture in a mare
}

\author{
Francisco J. Mendoza ${ }^{7}$, Miguel A. Valdes², Silvana Jimenez 3 , Maya Caparros², Francisco Enriquez ${ }^{3}$, Rosa Barsnick ${ }^{4}$ and Jose Carlos \\ Estepa ${ }^{7}$
}

Dept. Animal Medicine and Surgery, University of Cordoba, Spain?, Hospital de Referencia "La Equina", Manilva, Malaga, Spain², Ambulatory clinical practice, Cadiz, Spain ${ }^{3}$ and Pferdeklinik in Kirchheim, Kirchheim, Germany ${ }^{4}$

\begin{abstract}
Summary
A 8-year-old mixed-breed mare was presented to the Hospital with a 5 hours history of abdominal pain, reluctance to move, weakness and sweating. Abdominal ultrasonography revealed a large amount of echogenic peritoneal fluid with a swirling movement suggestive of hemoperitoneum. In addition, an intra-abdominal structure with an echogenic pattern similar to the spleen was identified. The case history and ultrasonographic findings supported the diagnosis of spontaneous splenic rupture as the cause of hemoperitoneum.
\end{abstract}

Keywords: hemoperitoneum, ultrasound, splenic rupture, equine, hemorrhage

\begin{abstract}
Hämoperitoneum nach Milzruptur bei einer Stute
Eine acht Jahre alte Mischlingsstute wurde mit Koliksymtomen vorgestellt. Die klinischen Symptome, wie Schwitzen und Bewegungsunlust, wurden seit fünf Stunden. Die transcutane sonographische Untersuchung des Abdomens ergab einen hochgradigen Peritonealerguss von erchogener Beschaffenheit mit wirbelartiger Bewegung, was auf ein Hämoperitoneum hinwies. Außerdem konnte eine intra-abdominale Stuktur mit echogenem, der Milz gleichendem, Muster dargestellt werden. Der Vorbericht und die sonografischen Befunde unterstützten die Diagnose einer spontanen, das Hämoperitoneum verursachenden Milzruptur.
\end{abstract}

Schlüsselwörter: Hämoperitoneum, Ultraschall, Milzruptur, Pferd, Hämorrhagie

\section{Introduction}

Hemoperitoneum has been widely studied in the last two decades and it is considered as an emergency in equine practice. Numerous underlying causes are associated with hemoperitoneum in both males and mares, and multiple tissues may lead to abdominal bleeding (Pusterla et al. 2005, Dechant et al. 2006).

The clinical signs of hemoperitoneum are variable depending on the underlying cause and the amount of blood loss. Often the horse is referred due to an acute onset of moderate to severe abdominal discomfort (Dechant et al. 2006). The diagnosis of abdominal bleeding is reached by the characteristic ultrasonographic appearance and the abdominocentesis yielding hemorrhagic fluid. In many occasions, it is difficult to identify the underlying cause, therefore, the treatment is directed towards the control of hemorrhage, hypovolemia and dehydration (maintenance of the cardiovascular state), to avoid secondary infections (Dechant et al. 2006), and to control the pain.

\section{Case description}

A 8-year-old mare, mix breed and weighting $460 \mathrm{Kg}$, was presented to the Hospital de Referencia La Equina with a 5 hours history of abdominal pain. The mare had not foaled or been pregnant for the last past two years. She was current on vaccinations (tetanus, rhinopneumonitis and influenza) and deworming. She was fed oats ( $2 \mathrm{~kg}$ twice a day), alfalfa hay ad libitum, and had free access to water. Abnormal physical examination findings included: depression, pale mucous membranes, increased capillary refill time (>3s), tachycardia (64 beats/min), tachypnea (32 breaths/min), reluctance to move, sweating, weakness and cool limbs. There were no significant findings on rectal palpation, no gastric reflux upon nasogastric intubation, and temperature $\left(38^{\circ} \mathrm{C}\right)$ as well as chest and abdominal sounds were found normal.

\section{Laboratory findings and interpretation}

Initial haematological analysis showed a slight anemia (Table 1). Creatinine and lactate concentrations were elevated, suggesting prerenal azotemia and impaired tissue perfusion due to likely to hypovolemia. On admission abdominocentesis yielded a haemorrhagic fluid with high content of red blood cells (PCV: 14\%), abundant degenerative neutrophils and peritoneal macrophages with evidence of erythrophagocytosis and an increased total protein concentration $(3.4 \mathrm{~g} / \mathrm{dL})$. Based on this, the peritoneal effusion was interpreted as hemoperitoneum. Twelve hours later, the packed cell volume and plasma total protein concentration decreased markedly, and the mare showed severe anemia (Table 1).

\section{Diagnostic imaging findings and interpretation}

Thoracic ultrasonography was unremarkable. In contrast, abdominal ultrasonography revealed the existence of a larged amount of echogenic peritoneal effusion, suggestive of high cellular content, with a swirling movement synchronized with diaphragmatic and abdominal organ motion (Figure 1). Differential diagnoses for a peritoneal effusion with a high cellular content were: exudate, modified transudate, 


\begin{tabular}{|c|c|c|}
\hline Hematological parameters. & & \\
\hline & Referring Vet & 12 hours later \\
\hline Packed cell volume (\%) & 28.20 & 11.40 \\
\hline Red blood cells $\left(\times 10^{6} / \mu\right.$ l) & 5.79 & 2.57 \\
\hline Hemoglobin $(\mathrm{g} / \mathrm{dl})$ & 8.90 & 4.20 \\
\hline MCV (fl) & 48.80 & 44.60 \\
\hline $\mathrm{MCH}(\mathrm{pg})$ & 15.30 & 16.30 \\
\hline $\mathrm{MCHC}(\mathrm{g} / \mathrm{dl})$ & 31.50 & 36.80 \\
\hline White blood cells $\left(\times 10^{3} / \mu\right.$ l) & 12.86 & 10.37 \\
\hline Granulocytes (\%) & 81.40 & 82.40 \\
\hline Monocytes (\%) & 4.20 & 4.00 \\
\hline Lymphocytes (\%) & 14.40 & 13.60 \\
\hline Platelets $\left(\times 10^{3} / \mu l\right)$ & 160 & 117 \\
\hline Total solids (g/dl) & 5.7 & 2.7 \\
\hline
\end{tabular}

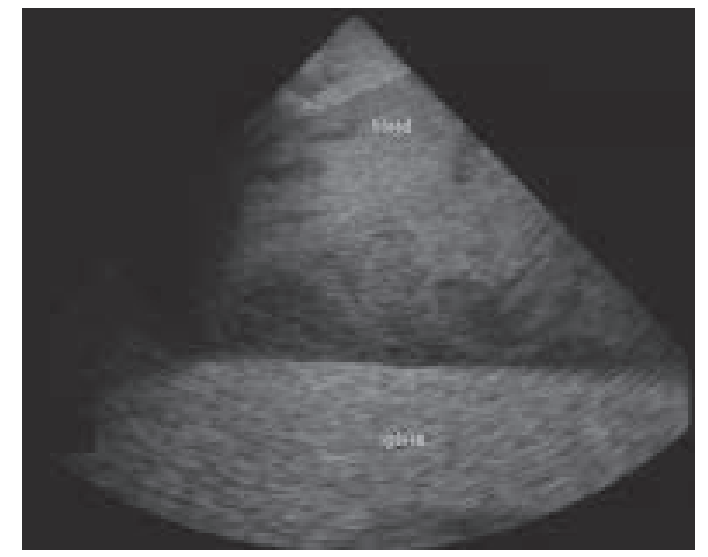

Fig. 1 Sonogram of the left paralumbar fossa obtained from a 8 -year-old mare with a 5 hours history of abdominal discomfort. This sonogram was obtained at submission with a $3.5 \mathrm{MHz}$ curved (convex) linear transducer operating at a displayed depth of 21 $\mathrm{cms}$. The left side of the sonogram is dorsal and the right side is ventral. Notice the large amount of peritoneal fluid of increased echogenicity suggestive of an elevated cellular content, pointing to hemoperitoneum.

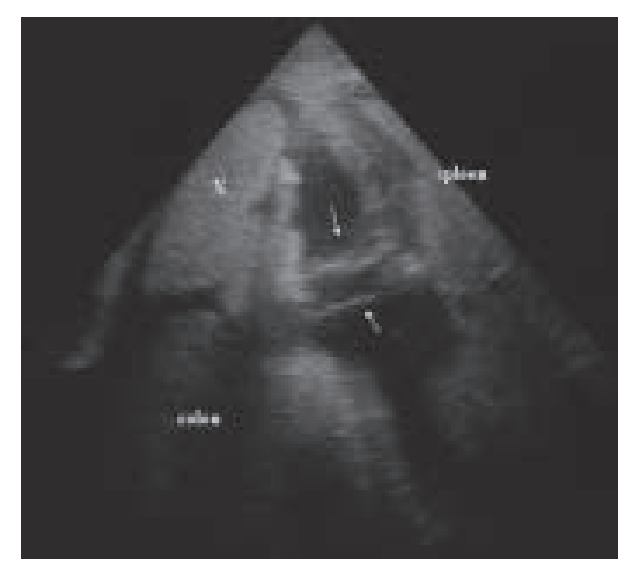

Fig. 2 Ultrasonographic picture obtained from the eleventh intercostal space $10-15 \mathrm{~cm}$ dorsally to the elbow joint with a 3.5 $\mathrm{MHz}$ curved (convex) linear transducer operating at a displayed depth of $23 \mathrm{cms}$. The left side of the sonogram is cranial and the right side is caudal. The image shows an intra-abdominal mass $(X)$ connected to the spleen by thin adhesions (arrows), presenting both structures similar echogenicity patterns. Note the irregular surface of both structures.

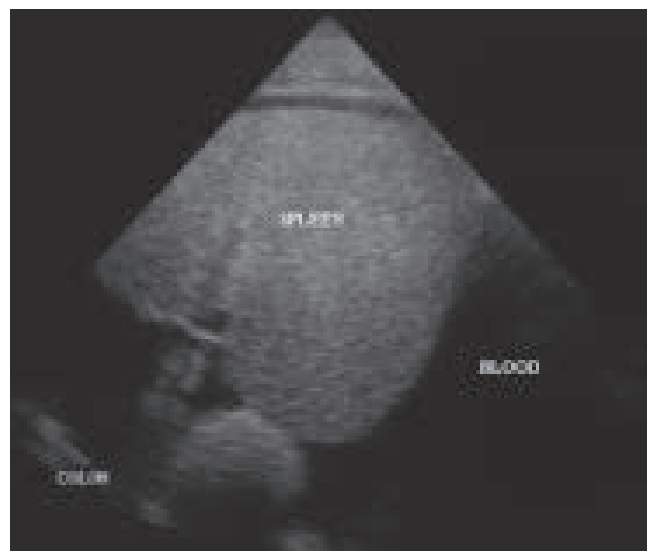

Fig. 3 Ultrasonographic image obtained from the left ventral side of the abdominal cavity. This picture was acquired with a 3.5 $\mathrm{MHz}$ curved (convex) linear transducer operating at a displayed depth of $23 \mathrm{cms}$. The left side of the sonogram is dorsal and the right side is close to the midline. In this sonogram is possible to observe a free intra-abdominal structure with an echogenic pattern similar to the spleen, with irregular margins and without continuity with the liver or other adjacent structure.

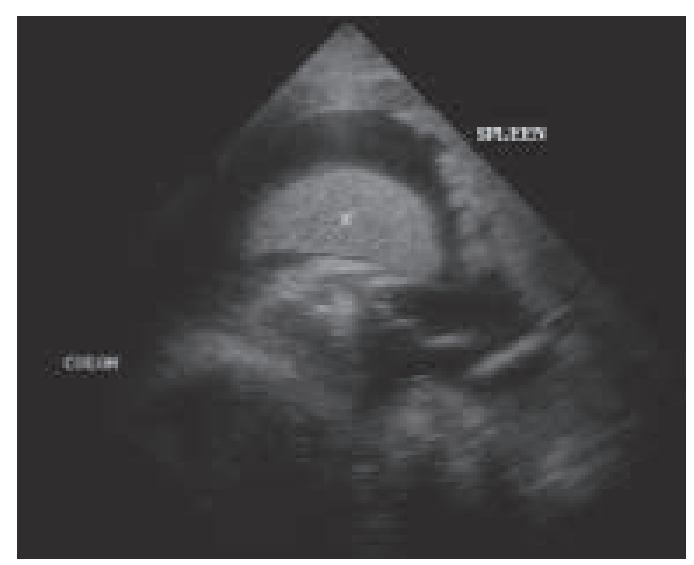

Fig. 4 Sonogram performed one day post-admission from the twelfth intercostal space 10-15 cm dorsally to the elbow joint, with a 3.5 MHz curved (convex) linear transducer operating at a displayed depth of $23 \mathrm{cms}$. The left side of the sonogram is cranial and the right side is caudal. The image shows a free mass $(X)$ not attached neither to the spleen nor to other organs. This mass shows the same echogenic pattern compared to the spleen. Note the irregular margin of the spleen suggestive of rupture. 
septic effusion, malignant effusion or hemoabdomen. Moreover, an intra-abdominal structure it was also detected, with a homogeneous echogenic pattern similar to the spleen, with irregular borders and connection to the spleen and adjacent organs by filamentary adhesions (Figures 2, 3 and 4). The differential diagnoses for this free mass were: a daughter spleen, splenic mass, folding of the spleen, a splenic hematoma, an abdominal mass, or a spontaneous splenic rupture.

\section{Treatment and outcome}

The mare was initially treated with resuscitation fluids $17.5 \%$ $\mathrm{NaCl}$ and Ringer lactate solutions) followed by crystalloids at maintenance rate (Ringer Lactate solution). In an attempt to reduce the intra-abdominal bleeding, aminocaproic acid (20 ml/kg IV diluted 1:9 in saline) was administered. To control inflammation and pain and to prevent endotoxemia and secondary infections, flunixin meglumine $(1.1 \mathrm{mg} / \mathrm{kg} \mathrm{IV}$, q 12 hours) and broad-spectrum antibiotics (potassium penicillin 22,000 iu/ $\mathrm{kg} \mathrm{IV,} \mathrm{q} 6$ hours and gentamicin sulphate $6.6 \mathrm{mg} / \mathrm{kg} \mathrm{IV,} \mathrm{q} 24$ hours) were administered. The mare was allocated in the critical care unit under minimal stress conditions and she was fed alfalfa hay and water ad libitum. Sixteen hours post-admission, due to further diminution of hematocrit and red cell count, a whole blood transfusion was performed (9 | IV). The mare was discharged one week post-admission with blood parameters within reference ranges.

\section{Discussion}

This report describes a case of a mare with abdominal discomfort, weakness, pale mucous membrane and reluctance to move. The abdominal ultrasound revealed a large amount of peritoneal fluid with increased echogenicity suggestive of hemoperitoneum which was confirmed by abdominocentesis. Based on the ultrasonographic findings a splenic rupture was the most likely cause of hemoperitoneum in this case. Once hemoperitoneum is suspected by ultrasonography (despite of the fact that the appearance is distinctive and almost pathognomonic), the diagnosis must be confirmed by abdominocentesis (Dechant et al. 2006), although it may be difficult to differentiate acute hemorrhage from iatrogenically induced hemorrhage (Pusterla et al. 2005).

The most common causes of hemoperitoneum are reproductive problems. It has been described multiple the possible reproductive underlying causes for abdominal bleeding in the mare. In this case, rupture of an ovary (granulosa or thecal cell neoplasia) (Gatewood et al. 1990, Alexander et al. 2004) was not the likely cause since neither sexual behaviour nor rectal palpation abnormalities were present. Moreover, rupture of the uterine or ovarian arteries was also ruled out because the mare was neither pregnant nor foaled within the past two years (Pascoe 1979). Other causes of hemoperitoneum in the periparturient mare are the uterine tears (Michiels et al. 2007). In the case reported here, the mare was neither pregnant nor foaled, and the abdominocentesis did not yield a suppurative inflammatory effusion, besides no uterine disruption was detected on rectal palpation.
Although less commonly, other causes of hemoperitoneum have been described in the literature. Despite of the fact that abdominal neoplasia (Southwood et al. 2000) or abscesses may lead to bleeding into the abdominal cavity, in this case neither transcutaneous abdominal ultrasonography nor rectal palpation revealed their existence, however it could not be completely discarded. Kidney diseases, such as pyelonephritis, nephrolithiasis or renal trauma have also been described as underlying causes of hemoperitoneum (Mitchell et al. 2004, Dechant et al. 2006), but in this case they could be ruled out since neither transabdominal ultrasonography nor renal biochemistry panel evidenced some abnormality. Liver disturbances have also been demonstrated causing abdominal bleeding in horses (Roby et al. 1990, Southwood et al. 2000). In our mare neither jaundice, increased hepatic enzymes, hyperlipemia nor chronic weight loss were evidenced.

This paper describes a case of hemoperitoneum most likely to due splenic rupture. Splenic rupture has been described as a consequence of tumors (hemangiosarcoma), hematomas located in the spleen, trauma of the splenic parenchyma during training or competitions, and spontaneous rupture in cases of viral infections, amyloidosis or thrombocytopathy (Finocchio 1971, Dyke and Friend 1998, Mehl et al. 1998). In this case, the performed blood work did not include clotting times to rule out thrombocytopathy, and biopsy of the spleen was not considered to rule out viral infections or disseminated neoplasia. However, the clinical examination and the laboratory findings did not show any significant changes indicative of viral or bacterial infection, hematological manifestations or other hypocoagulable tendencies (injection points, nasal or mucosal bleeding). Moreover, the echogenic pattern of the spleen did not show any differences to that of normal spleen, while usually splenic neoplasia presents as a nodular parenchyma, and/or changes of echogenicity and size. The ultrasonographic findings in this clinical case also may be suggestive of splenic hematoma (Mehl et al. 1998), a previous healed splenic fracture or folding of the spleen, but the connections between the spleen and the free mass fractured from the spleen, excluded these causes of hemoperitoneum. Splenic rupture has been reported to be associated with trauma or with nontraumatic pathologic splenic rupture (Orloff et al. 1958). In the case reported here neither superficial injury nor traumatism were detected or documented by the owner. A true "spontaneous" nontraumatic ruptured of a nondiseased spleen is extremely rare (Orloff et al. 1958). In human medicine it has been described secondary to hematological malignancies as leukemia and lymphoma, Epstein-Barr virus, malaria, HIV and pancreatitis (Rhee et al. 2008).

Antihaemorrhagic drugs are often administrated to stop the haemorrhage in horses. Although its effectiveness is controversial, they are widely used in equine medicine in order to potentiate the coagulation mechanism rather than to correct the coagulation deficits. Aminocaproic acid is one of the most common antihaemorrhagic drugs used in horses. Despite of the fact that it is an antifibrinolytic drug, irreversible binding to plasminogen, it has been reported that it reduces bleeding (Smith 2003).

In conclusion, this clinical work describes a case of hemoperitoneum secondary to a rare incident of spontaneous splenic 
rupture. Furthermore, to our knowledge, this is the first time that images of hemoperitoneum due to a splenic rupture in a mare are reported.

\section{References}

Alexander G. R., Tweedie M. A., Lescun T. B. and McKinnon A. Q. (2004) Haemoperitoneum secondary to granulosa cell tumor in two mares. Aust. Vet. J. 82, 481-484

Dechant J. E., Nieto J. E. and Le Jeune S. S. (2006) Hemoperitoneum in horses: 67 cases (1989-2004). J. Am. Vet. Med. Assoc. 229, 253-258

Dyke T. M. and Friend S. C. (1988) Ruptured splenic haematoma in a mare. Equine Vet. J. 20, 138-140

Finocchio E. J. (1971) Splenic rupture in a horse. Vet. Med. Small. Anim. Clin. 66, 223

Gatewood D. M., Douglass J. P., Cox J. H., DeBowes R. M. and Kennedy G. A. (1990) Intra-abdominal hemorrhage associated with a granulosa-thecal cell neoplasm in a mare. J. Am. Vet. Med. Assoc. 196, 1827-1828

Mehl M. L., Ragle C. A., Mealey R. H. and Whooten T. L. (1998) Laparoscopic diagnosis of subcapsular splenic hematoma in a horse. J. Am. Vet. Med. Assoc. 213, 1171-1173

Michiels I., de Valck C., de Loor J., Hendriks J., Jacquemyn Y. and Tialma W. A. (2007) Spontaneous uterine rupture during pregnancy, related to a horse fall 8 weeks earlier. Acta Obstet. Gynecol. Scand. 86, 380-381

Mitchell K. J., Dowling B. A., Hughes K. J. and Dart A. J. (2004) Unilateral nephrectomy as a treatment for renal trauma in a foal. Aust. Vet. J. 82, 753-755
Orloff M. and Peskin G. W. (1958) Spontaneus rupture of the normal spleen, a surgical enigma. Int. Abstr. Surg. 106, 1-11

Pascoe R. R. (1979) Rupture of the utero-ovarian and middle uterine artery in the mare at or near parturition. Vet. Rec. 104, 77

Pusterla N., Fecteau M. E., Madigan J. E., Wilson W. D. and Magdesian K. G. (2005) Acute hemoperitoneum in horses: a review of 19 cases (1992-2003). J. Vet. Intern. Med. 19, 344-347

Rhee S. J., Sheena Y. and Imber C. (2008) Spontaneous rupture of the spleen: a rare but important differential of an acute abdomen. Am. J. Emerg. Med. 26, 733.e5-e6

Roby K. A., Beech J., Bloom J. C. and Black M. (1990) Hepatocellular carcinoma associated with erythrocytosis and hypoglycaemia in a yearling filly. J. Am. Vet. Med. Assoc. 196, 465-467

Smith C. L. (2003) Critical care therapeutics for mature horses. Current therapy in equine medicine, WB Saunders, Philadelphia, Fifth edition, pp 19-23

Southwood L. L., Schott H. C., Henry C. J., Kennedy F. A., Hines M. T., Geor R. J. and Hassel D. M. (2000) Disseminated hemangiosarcoma in the horse: 35 cases. J. Vet. Intern. Med. 14, 105-109

Miguel A. Valdes DVM, ACVS, ECVS

Hospital de Referencia La Equina

Apdo. 7 10. Camino de Martagina Km 1

29692 Manilva (Malaga)

Spain

miguel@laequina.com 